\title{
Evaluation of the thermal performance of a building in light steel framing in Manaus-AM
}

\author{
Tatiusse Ferreira da Silva ${ }^{1}$
}

${ }^{1}$ Uninorte Laureate International. Av. Joaquim Nabuco, No 1270. Centro. Manaus - Amazonas. Brasil. CEP:69020-030.

Email: tatiusse ferreira@ hotmail.com

Received: December $22^{\text {th }}, 2016$

Accepted: January $17^{\text {th }}, 2017$

Published: Mach 30th, 2017

Copyright (C2016 by authors and Institute of Technology Galileo of Amazon (ITEGAM). This work is licensed under the Creative Commons Attribution International License (CC BY 4.0).

http://creativecommons.org/licenses/by/4.0/ (c) (1) (3) (2) Opean Actes:

\begin{abstract}
This study aimed to verify the thermal performance of a building built with the construction system Light Steel Framing in Manaus-AM, by evaluating the thermal performance of buildings, with the application of the requirements and criteria of the seal and cover systems due to need for thermal comfort in hot and humid climates, as well as identify the bioclimatic zone of the city of Manaus, characterize the geometry of the building with the requirements and criteria for assessing air vents, external wall and roof, and then determine the transmittance and thermal capacity. Therefore, we used methodically to collect data literature search, the search and allocation of knowledge about the thermal performance of buildings, and addressing the simplified procedure of analysis that uses the requirements proposed by NBR 15,575 / 2013 for analysis thermal performance of buildings.
\end{abstract}

Keywords: light Steel Framing, thermal performance, evaluation of the thermal performance of buildings.

Avaliação do desempenho térmico de uma edificação em light steel framing na cidade de Manaus-AM

\section{RESUMO}

Esse estudo objetivou verificar o desempenho térmico de uma edificação construída com o sistema construtivo Light Steel Framing na cidade de Manaus-AM, através da avaliação do desempenho térmico de edificações, com a aplicação dos requisitos e critérios dos sistemas de vedação e cobertura, devido a necessidade de conforto térmico em regiões de clima quente e úmido, bem como identificar a zona bioclimática da cidade de Manaus, caracterizar a geometria da edificação com os requisitos e critérios de avaliação das aberturas para ventilação, parede externa e cobertura, para então determinar a transmitância e capacidade térmica. Para tanto, foi utilizado com método para coleta de dados a pesquisa bibliográfica, na busca e alocação de conhecimento sobre o desempenho térmico de edificações, e abordando o procedimento simplificado de análise, que utiliza os requisitos propostos pela ABNT NBR 15.575/2013 para análise do desempenho térmico de edificações.

Palavras Chaves: light Steel Framing; desempenho térmico; avaliação do desempenho térmico de edificações.

\section{INTRODUÇÃO}

A Avaliação de desempenho térmico das edificações busca analisar a adequação ao uso de um sistema construtivo destinado a cumprir uma função. Para atingir esta finalidade, é realizada uma investigação baseada em métodos consistentes, que gera uma interpretação sobre o comportamento do sistema nas condições de uso definidas [1].

Desta forma a avaliação do desempenho térmico de uma edificação na cidade de Manaus-AM, que abrange uma área urbana de $11.401,092 \mathrm{~km}^{2}$ e mais de 1,8 milhões de habitantes (IBGE, 2010), com clima caracterizado como quente e úmido predominante da região Amazônica [2], busca verificar o desempenho térmico 
dessa edificação, devido a necessidade de conforto térmico em regiões de clima quente e úmido, onde verifica-se o emprego do sistema construtivo Light Steel Framing (LSF).

O sistema construtivo LSF, é constituído de vedações externas leves, de pouca massa, e isolamento térmico integrado, prometendo um desempenho térmico superior aos sistemas construtivos convencionais. De acordo com [3] "uma boa escolha do sistema construtivo na fase de projeto é determinante, para que não comprometa o desempenho da edificação e conforto térmico dos usuários". A confiança na utilização desse sistema construtivo, vem se desenvolvendo no Sul do pais, mas sua relação com o assunto "desempenho térmico" no norte do Brasil é objeto de perguntas e algumas dúvidas recorrentes.

A respeito deste cenário, o objetivo do estudo foi verificar o desempenho térmico de uma edificação em LSF na cidade de Manaus-AM, através da avaliação do desempenho térmico de edificações com a aplicação dos requisitos e critérios da norma de desempenho de habitações da [1]. Levando em conta a zona bioclimática e as recomendações das diretrizes construtivas de adequação ao clima local, para verificar se a edificação atende aos níveis mínimos de desempenho exigidos por esta norma.

Dessa forma, procede-se com a identificação da zona bioclimática para identificar as estratégias e critérios para se caracterizar a edificação de acordo com as diretrizes construtivas da região, e avaliar através do procedimento de avaliação simplificado da norma [1], e da metodologia de cálculo das propriedades térmicas - transmitância e capacidade térmica das paredes externas e cobertura [4].

Devido a necessidade de conforto térmico em regiões de clima quente e úmido, esse estudo se justifica através de uma realização da avaliação do desempenho térmico da edificação de LSF, em contribuição para o seu público alvo a vantagem do uso dessa tecnologia construtiva na cidade, esclarecendo dúvidas em relação ao conforto térmico do clima quente e úmido de Manaus, com base nas normas da ABNT, de desempenho de habitações [1] e da avaliação de desempenho térmico de edificações [5].

Para amenizar a sensação de desconforto térmico, adotase estratégias construtivas e ventilação natural, utilizando os recursos naturais. Para [6] "o desempenho térmico de edificações é um fator importante, e uma edificação projetada para o clima no qual está inserida torna-se confortável", e para [7], "o clima quente e úmido é o mais difícil do ponto de vista do design térmico, onde o ideal é se assegurar que as condições internas não sejam piores que as externas, o que não é uma tarefa muito fácil”.

Para o desenvolvimento do presente trabalho e um melhor tratamento dos objetivos, ouve necessidade da pesquisa bibliográfica no momento em que se fez uso de materiais já publicado, constituído principalmente de livros, Normas Técnicas, Dissertações e Teses, na busca e alocação de conhecimento sobre o Desempenho térmico de Edificações, correlacionando tal conhecimento com abordagens já trabalhadas por outros autores. Logo, se focará no procedimento 1 dito simplificado da norma [1] onde o atendimento aos requisitos e critérios para verificação dos níveis mínimos de desempenho térmico dos sistemas de vedação e cobertura é dado conforme as [1][4].

\section{REVISÃO BIBLIOGRÁFICA}

Tendo em vista que, a construção civil vem em busca de sistemas inovadores, com menos perdas e sempre com o objetivo de proteger o meio ambiente, o Light Steel Framing surge como uma boa solução. É um sistema construtivo moderno, e vem conquistando espaço no mercado da construção civil brasileiro.
Segundo [8] "[...] no Brasil, essa tecnologia é recente, e somente no final da década de 90 esse sistema começou a ser introduzido no país para a montagem de casas residenciais, por ser um sistema importado, ainda há algumas adaptações climáticas dos projetos a serem feitas". Todavia, o LSF gera edificações com aspecto final semelhante ao da construção convencional, figura 1, a sua estrutura nunca se exibe aparente, integra tecnologia, resistência e sustentabilidade.

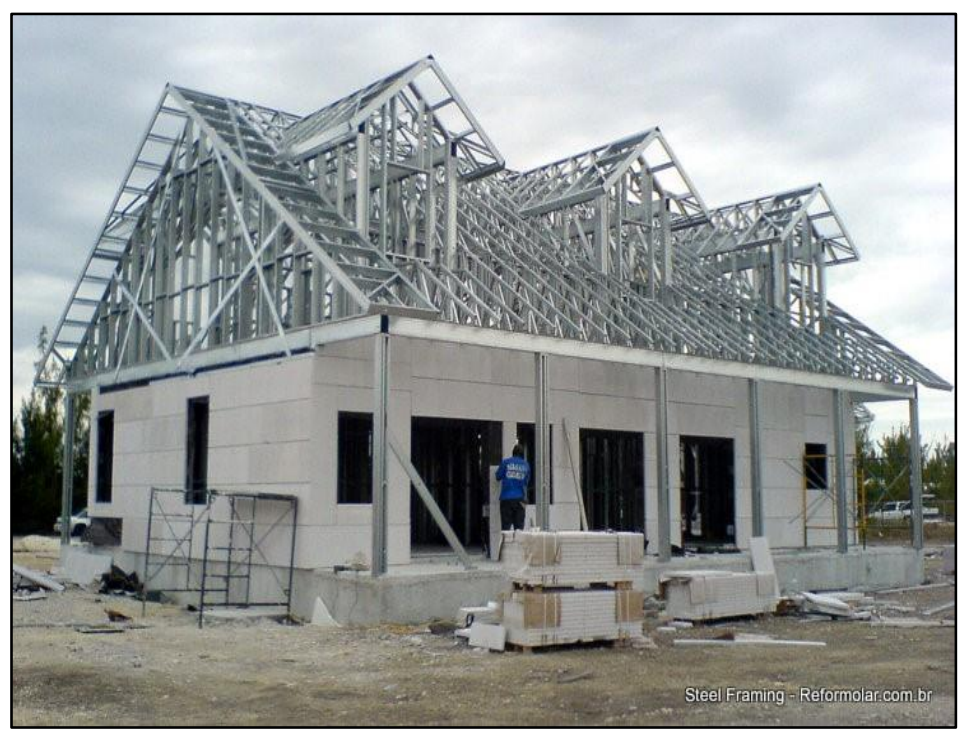

Figura 1:Modelo de Residência em LSF.

Fonte: [9].

No Manual Steel Freme - Arquitetura do CBCA, basicamente a estrutura em LSF é composta de paredes, pisos e cobertura que juntos, possibilitam a integridade estrutural da edificação, resistindo aos esforços que solicitam a estrutura. As estruturas das paredes são de painéis que tem a função de distribuir as cargas uniformemente, encaminhando para a fundação e consequentemente para o solo, são compostos por perfis de aço galvanizado, que de acordo com o cálculo estrutural são definidos os espaçamentos entre os montantes de 400 a $600 \mathrm{~mm}$.

A realização de avaliação do desempenho térmico de uma edificação na cidade de Manaus, capital do Amazonas, que está localizada em uma microrregião denominada "Médio Amazonas", distante $1.700 \mathrm{~km}$ em linha reta do litoral e é considerada por estudiosos como a verdadeira capital da Amazônia Brasileira por localizar-se entre a Amazônia Ocidental e Oriental [7], sua posição geográfica é de $60^{\circ}$ de longitude oeste e $3^{\circ} 08^{\prime}$ de latitude sul e uma altitude média de 92,9 m., abrange uma área urbana de 11.401,092 $\mathrm{km}^{2}$ e mais de 1,8 milhões de habitantes [10], e está localizada na zona bioclimática oito de acordo com a [4] seguindo essas características, verifica-se o emprego do sistema construtivo em LSF para essa região, que apresenta segundo o [11] duas estações distintas: a Chuvosa (inverno), de dezembro a maio; e a Seca (verão), de junho a novembro, período de sol intenso e temperatura média acima de $35^{\circ} \mathrm{C}$.

O clima da cidade de Manaus segundo [2], "se caracterizada, como sendo um clima tropical, quente e úmido predominante da região Amazônica". E para amenizar a sensação de desconforto térmico, adota-se estratégias construtivas e ventilação natural para se proporcionar o conforto, utilizando os recursos naturais. Um desempenho térmico satisfatório da edificação, com a utilização apenas de recursos naturais, pode não ser possível em 
condições climáticas muito rígidas, contudo devem-se procurar propostas que maximizem o desempenho térmico natural, pois, assim pode-se reduzir uso de resfriamento artificial necessário para amenizar a sensação de desconforto térmico por calor [12].

Entende-se que com uma ventilação natural, através de janelas posicionadas em localidades estratégicas da edificação, pode-se maximizar o desempenho térmico da edificação, amenizando as altas temperaturas e possibilitando conforto térmico. Para [7], "o clima quente e úmido é o mais difícil do ponto de vista do design térmico, onde o ideal é se assegurar que as condições internas não sejam piores que as externas, o que não é uma tarefa muito fácil".

Em virtude disso, destaca-se que a cidade de Manaus tem passado por processos de ampliação e de remodelação de seu espaço físico e transformações em sua arquitetura, onde novas técnicas e materiais estão sendo incorporados ao processo construtivo. Algumas destas técnicas não são de uso recomendável em virtude das características ambientais da região [13].

É determinante uma boa escolha do sistema construtivo na fase de projeto. Trata-se inegavelmente de uma escolha para a sensação de conforto térmico, um sistema que já na sua concepção está voltado para o desempenho térmico da edificação, seria um erro, porém, não atribuir que o clima quente e úmido é o mais difícil do ponto de vista do design térmico.

Assim, reveste-se de particular importância as características ambientais da região. Sob essa ótica, ganha particular relevância as novas técnicas e materiais que são utilizados no sistema construtivo do Light Steel Framing. "O desempenho térmico de edificações é um fator importante, e uma edificação projetada para o clima no qual está inserida torna-se confortável".

O guia do Desempenho de edificações habitacionais, que orienta no atendimento à norma [1], aborda que o desempenho térmico depende de diversas características do local da obra e da edificação, a sensação de conforto térmico depende muito das condições de ventilação dos ambientes, influenciado pelo posicionamento, como também as dimensões da janela, dessa forma, quando se trata de conforto térmico, está se referindo sempre a uma condição media que atende a maior parte das pessoas expostas a uma determinada condição [14].

A sensação de conforto térmico, por vezes está ligada ao desempenho térmico da edificação. Para [3] que expõe claramente que a escolha do sistema construtivo, para determinadas regiões se relaciona diretamente com o desempenho e conforto térmico da edificação. Neste contexto, fica claro que, a edificação deve ser projetada diretamente para o clima local.

O mais preocupante, contudo, é constatar que o desempenho térmico da edificação localizada no clima quente e úmido, gera ou não uma sensação de conforto térmico. Mas, podese dizer que o desempenho térmico com relação ao sistema construtivo Light Steel Framing, pode ser obtido, contudo, trata-se de adequar a edificação as estratégias construtivas adequas para o clima local.

\section{MATERIAIS E MÉTODOS}

A metodologia empregada nesse estudo se estabelece da aplicação do procedimento simplificado, de caráter normativo, encontrado na norma [1], para analisar o desempenho térmico de uma edificação térrea unifamiliar, e a base de cálculo das propriedades térmicas dos elementos, Transmitância Térmica (U) e Capacidade Térmica $(\mathrm{Ct})$, necessária para análise da edificação, são determinadas na [4].

\section{III.1 ZONEAMENTO BIOCLIMÁTICO BRASILEIRO}

Para caracterização do clima, analisou-se a [5], em que a cidade Manaus-AM, foi verificada que se encontra na zona bioclimática oito, onde na norma foi tomada como referência a cidade de Belém-PA, que se tratando da mesma zona bioclimática poderá ser utilizada nesse estudo, detalhes da figura 2 , a região de cor amarela, determina a zona bioclimática oito e suas diretrizes construtivas.

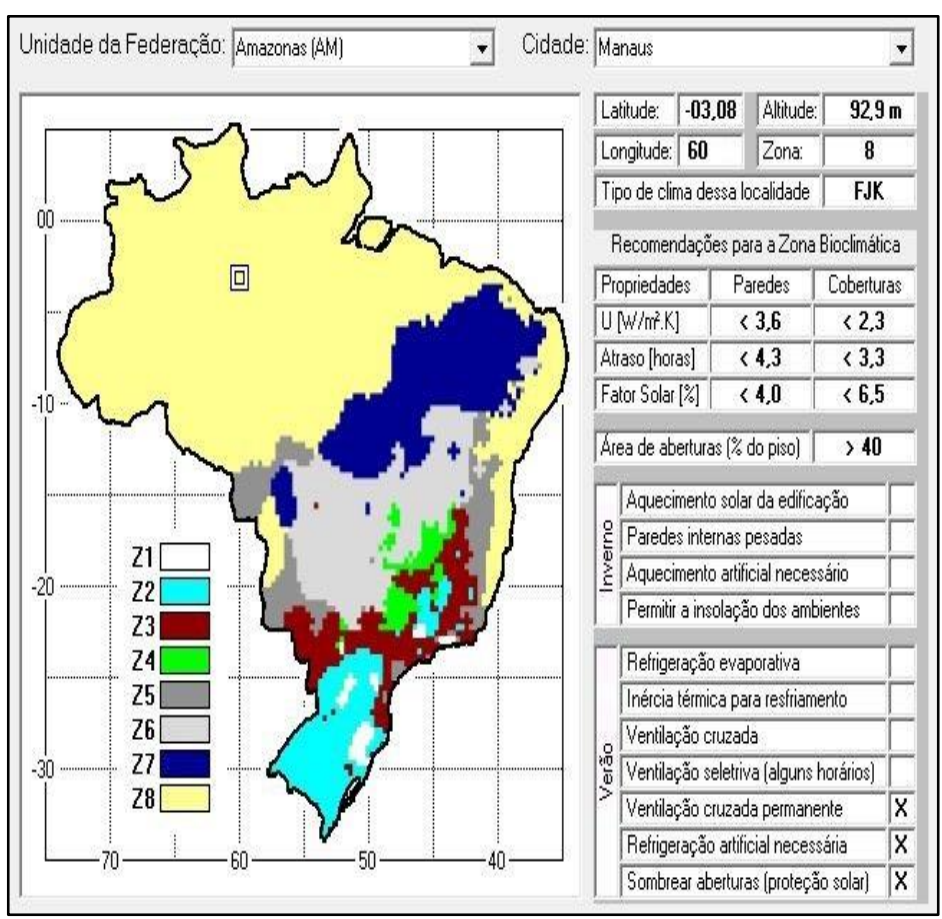

Figura 2 - Zona bioclimática da Região.

Fonte: [5].

Observa-se que as aberturas do tipo "Grande" e "sombreada" tem relação a área de abertura de ventilação com a área do piso, e o sombreamento com a utilização de brises, marquises ou toldos. A ventilação cruzada ocorre quando existem no mínimo duas aberturas em lados opostos dos ambientes, permitindo a completa circulação do ar. O posicionamento das aberturas deve levar em conta a incidência dos ventos dominantes de cada região.

\section{III.2 CARACTERIZAÇÃO DA EDIFICAÇÃO}

A edificação analisada é uma residência unifamiliar térrea de $64,80 \mathrm{~m}^{2}$, pé-direito de $3,00 \mathrm{~m}$, com sala, cozinha, um dormitório e uma suíte, banheiro e ático (espaço entre a laje de teto e o telhado), para se adequar ao sistema construtivo de Light Steel Framing, atenderam-se as recomendações de [6], adicionado uma malha geométrica modular de 600 por $600 \mathrm{~mm}$, sem necessidade de distância maior entre os montantes, detalhes figura 3.

A fundação comumente utilizada nas edificações residenciais em LSF é tipo radier, uma fundação rasa que funciona como uma laje, transmitindo as carcas da estrutura para solo. 


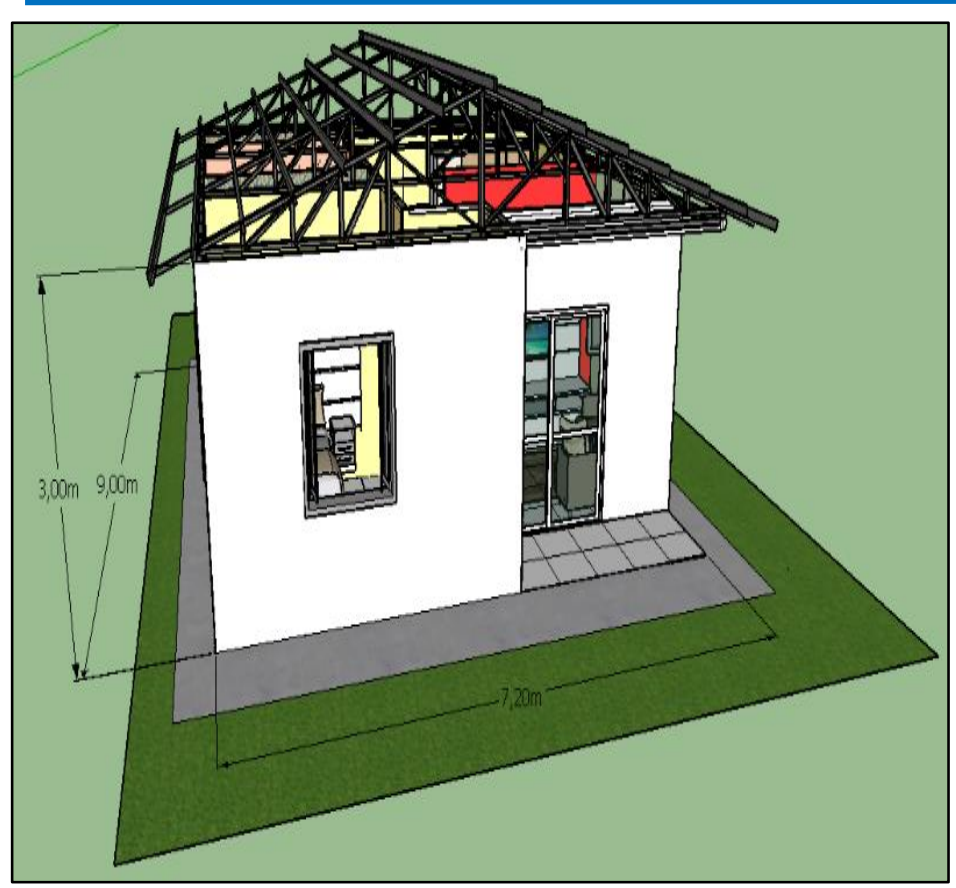

Figura 3: Edificação em LSF.

Fonte: A autora, 2016.

Os requisitos e critérios de aberturas para ventilação da edificação devem ter dimensões apropriadas nos ambientes de longa permanência, salas, cozinhas e dormitórios, para proporcionar a ventilação interna dos ambientes, onde devem ter abertura que atendam a legislação especifica do local da obra e para os valores da área mínima de ventilação são apresentados de acordo com a zona bioclimática [1], conforme apresenta a tabela 1 .

Tabela 1: Ventilação

\begin{tabular}{|c|c|c|c|c|c|}
\hline \multirow{2}{*}{\multicolumn{2}{|c|}{$\begin{array}{c}\text { ABNT NBR } \\
\text { n15575-4 - Zona } 8 \\
\text { Nível Mínimo de } \\
\text { Desempenho }\end{array}$}} & \multirow{2}{*}{$\begin{array}{l}\text { Plano } \\
\text { Diretor }\end{array}$} & \multirow{2}{*}{ Ambiente } & \multirow{2}{*}{$\operatorname{Ap}\left(\mathbf{m}^{2}\right)$} & \multirow{2}{*}{$\begin{array}{l}\text { Abertu } \\
\text { ra p/ } \\
\text { ventila } \\
\text { ção }(\mathrm{A})\end{array}$} \\
\hline & & & & & \\
\hline \multirow{4}{*}{ 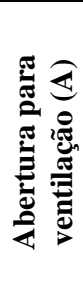 } & \multirow{4}{*}{$\begin{array}{c}\mathrm{A} \geq 12 \% \\
\text { da área do } \\
\text { piso } \\
\text { REGIAO } \\
\text { NORTE } \\
\text { DO } \\
\text { BRASIL }\end{array}$} & \multirow{4}{*}{$\begin{array}{l}\mathrm{A} \geq 1 / 5 \\
\text { da área } \\
\text { total do } \\
\text { compar } \\
\text { timento }\end{array}$} & Dormitório & 12,96 & $25 \%$ \\
\hline & & & Suíte & 9,00 & $27 \%$ \\
\hline & & & Sala & 9,00 & $27 \%$ \\
\hline & & & Cozinha & 10,8 & $22,5 \%$ \\
\hline
\end{tabular}

Fonte: Adaptada de [20].

Observa-se que a abertura para a região norte é maior que $12 \%$ e conforme o $\operatorname{Art}^{\circ} 60$ do Código de Obras e Edificações do Município de Manaus (Lei complementar $n^{\circ} 3$, de 16 de janeiro de 2014), estabelece que as aberturas para ventilação e iluminação deverão atender a 1/5 (um quinto) da área total do compartimento. Abaixo as áreas de cada ambiente, figura 4.

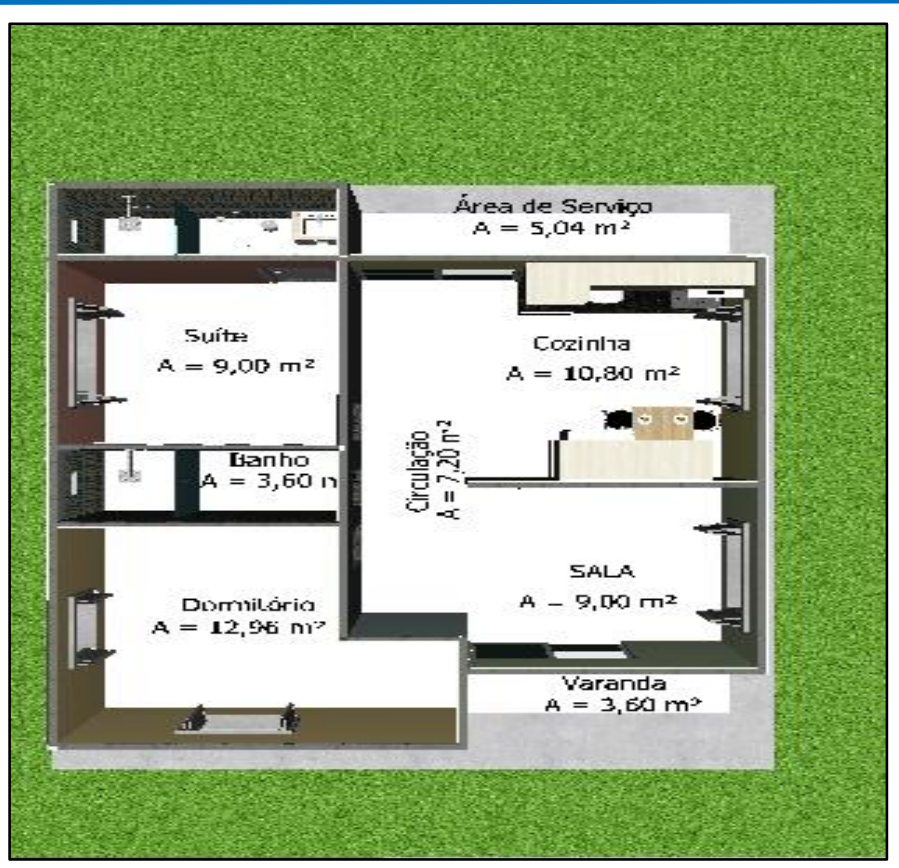

Figura 4: Croqui da edificação em LSF.

Fonte: A autora, 2016.

\section{III.3.2.1 FECHAMENTO EXTERNO DA EDIFICAÇÃO}

Foi estabelecida como base nos estudos de [8][16], são painéis comumente utilizados em edificações de LSF no Brasil, painéis esses, estruturais, que tem a função de absorver e distribuir as cagas para a fundação. Os fechamentos externos empregados são de placas cimentícias na camada externa e placas de gesso acartonado na camada interna, seu interior, são preenchidos com lã de vidro material que apresenta alto desempenho em isolamento térmico e acústico, assim como uma camada de ar, e por fim o perfil montante em U enrijecido (90x40) de aço galvanizado, com 0,95 $\mathrm{mm}$ de espessura, figura 5 , espaçados entre si de acordo com a modulação definida de $600 \mathrm{~mm}$.

O LSF, é originalmente formado com a cavidade totalmente preenchida por isolante térmico. Porém, no Brasil, para reduzir os custos, as empresas empregam uma quantidade menor do isolante, logo cria-se uma camada de ar dentro do fechamento [17].

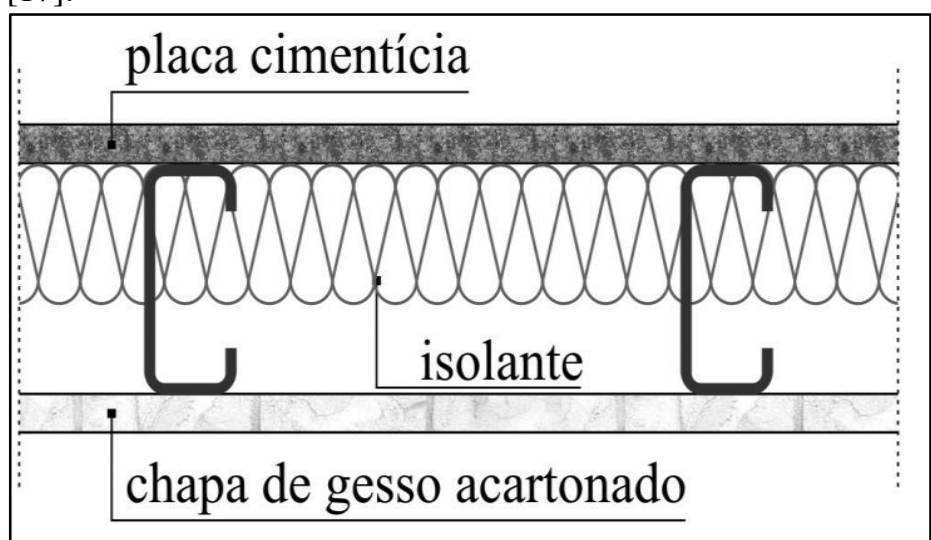

Figura 5: Detalhe fechamento externo.

Fonte: Adaptada de [16].

Os Requisitos e Critérios de verificação das vedações verticais externas conforme a zona bioclimática estabelecida na [5], a transmitância térmica e capacidade térmica das paredes externas, devem apresentar valores máximos aceitáveis de acordo com a tabela 2. Os requisitos de desempenho, expressam as condições dos 
atributos, para satisfazer as exigências dos usuários de uma edificação e seus sistemas. Esses requisitos são aplicáveis somente para edificações de até cinco pavimento.

Já os critérios, são determinação das especificações dos requisitos de desempenho quantitativos [1].

Tabela 2: Critério - Transmitância e Capacidade Térmica das Paredes.

\begin{tabular}{|c|c|c|}
\hline $\begin{array}{c}\text { Absortância a radiação } \\
\text { solar da superfície } \\
\text { externa da parede }\end{array}$ & $\begin{array}{c}|c| \\
\text { Zona Bioclimática 8 } \\
\text { Térmica W/m² } \mathbf{~} \mathbf{k}\end{array}$ & $\begin{array}{c}\text { Capacidade } \\
\text { térmica }\end{array}$ \\
\hline$\alpha \leq 0,6$ & $\mathrm{U} \leq 3,7$ & \multirow{2}{*}{ Sem exigência } \\
\hline$\alpha>0,6$ & $\mathrm{U} \leq 2,5$ & \\
\hline
\end{tabular}

Fonte: Adaptada de [20].

\section{III.3.2.1.1METODOLOGIA DE CÁLCULO DA TRANSMITÂNCIA E CAPACIDADE TÉRMICA DAS PAREDES EXTERNAS}

Primeiramente serão analisadas a propriedade da transmitância térmica da parede, calculando primeiro a resistência térmica com a equação 1 , pois a Transmitância térmica é o inverso da Resistencia Térmica total de ambiente a ambiente do componente.

Procede-se com o cálculo da resistência térmica total de ambiente a ambiente, com a utilização da equação 2, que são levadas em conta as resistências interna e externa, tabela 4, como também a resistência térmica de superfície a superfície juntamente com a resistência da câmara de ar não ventilada, tabela 5, para resistência superfície a superfície do fechamento utiliza a equação 3 , e a resistência de cada elemento, utiliza-se a equação 4 , com a espessura e condutividade térmica de cada camada. Verifica-se todas essas equações na tabela 3 .

Tabela 3:Equações para obtenção da Transmitância térmica do fechamento.

\begin{tabular}{|c|c|c|c|}
\hline Equação 1 & Equação 2 & Equação 3 & Equação 4 \\
\hline $\begin{array}{l}\mathrm{U}=1 / \mathrm{R}_{\mathrm{T}} \\
\left(\mathrm{W} / \mathrm{m}^{2} \mathrm{k}\right)\end{array}$ & $\begin{array}{c}\mathrm{R}_{\mathrm{t}}=\mathrm{R}_{\mathrm{SE}}+ \\
\mathrm{R}_{\mathrm{t}}+\mathrm{R}_{\mathrm{SI}} \\
\left(\mathrm{m}^{2} . \mathrm{K} / \mathrm{W}\right)\end{array}$ & $\begin{array}{c}\mathrm{R}_{\mathrm{t}}=\mathrm{R}_{\mathrm{t} \text { gesso }} \\
\text { acartonado }+\mathrm{R}_{\mathrm{t} \text { lã de }} \\
\text { vidro }+\mathrm{R}_{\mathrm{ar}}+\mathrm{R}_{\mathrm{t}} \\
\text { placa cimentícia } \\
\left(\mathrm{m}^{2} . \mathrm{K} / \mathrm{W}\right)\end{array}$ & $\begin{array}{l}\mathrm{R}_{\mathrm{t}} \mathrm{I}=\mathrm{e}_{\mathrm{I}} / \lambda_{\mathrm{i}} \\
\left(\mathrm{m}^{2} \cdot \mathrm{K} / \mathrm{W}\right)\end{array}$ \\
\hline
\end{tabular}

Fonte: Adaptada da[4].

Analisando a tabela 4, abaixo, considerou-se que os valores que serão adotados em relação a $R_{S E}$ e $R_{S I}$ são com a direção do fluxo de calor horizontal nas paredes, logo os valores são 0,13 e 0,4 respectivamente. A resistência térmica da câmara de ar não ventilada, varia de acordo com a direção do fluxo de calor, espessura e a emissividade do componente, e pode ser determinada na tabela 5.

Tabela 4: Resistência térmica superficial interna e externa.

\begin{tabular}{|c|c|c|c|c|c|}
\hline \multicolumn{3}{|c|}{$R_{\mathrm{si}}\left(\mathrm{m}^{2} \cdot \mathrm{K}\right) \mathrm{W}$} & \multicolumn{3}{|c|}{$R_{s e}\left(m^{2} \cdot K\right) W W$} \\
\hline \multicolumn{3}{|c|}{ Direção do fluxo de calor } & \multicolumn{3}{|c|}{ Direção do fluxo de calor } \\
\hline Horizontal & Ascendente & Descendente & Horizontal & Ascendente & Descendente \\
\hline$\Rightarrow 1$ & $\mathrm{~A}$ & 8 & $\Rightarrow 1$ & 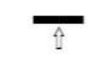 & \& \\
\hline 0,13 & 0,10 & 0,17 & 0,04 & 0,04 & 0,04 \\
\hline
\end{tabular}

Fonte: [4].
Tabela 5: Resistência da Câmara de ar não ventilada.

\begin{tabular}{|c|c|c|c|c|}
\hline \multirow{4}{*}{$\begin{array}{l}\text { Natureza da } \\
\text { superficie da } \\
\text { câmara de ar }\end{array}$} & \multirow{4}{*}{$\begin{array}{c}\text { Espessura "e" da } \\
\text { câmara de ar } \\
\mathrm{cm}\end{array}$} & \multirow{2}{*}{\multicolumn{3}{|c|}{$\begin{array}{l}\text { Resistência térmica } R_{\mathrm{ar}} \\
\mathrm{m}^{2} \mathrm{KW}\end{array}$}} \\
\hline & & & & \\
\hline & & Horizontal & Ascendente & Descendente \\
\hline & & $|\Rightarrow|$ & $\overline{\hat{\pi}}$ & $\bar{n}$ \\
\hline $\begin{array}{l}\text { Superficie de alta } \\
\text { emissividade } \\
\varepsilon>0,8\end{array}$ & $\begin{aligned} 1,0 & \leq e \leq 2,0 \\
2,0 & <e \leq 5,0 \\
e & >5,0\end{aligned}$ & $\begin{array}{l}0,14 \\
0,16 \\
0,17\end{array}$ & $\begin{array}{l}0,13 \\
0,14 \\
0,14\end{array}$ & $\begin{array}{l}0,15 \\
0,18 \\
0,21\end{array}$ \\
\hline $\begin{array}{c}\text { Superficie de baixa } \\
\text { emissividade } \\
\varepsilon<0,2\end{array}$ & $\begin{array}{c}1,0 \leq e \leq 2,0 \\
2,0<e \leq 5,0 \\
e>5,0\end{array}$ & $\begin{array}{l}0,29 \\
0,37 \\
0,34\end{array}$ & $\begin{array}{l}0,23 \\
0,25 \\
0,27\end{array}$ & $\begin{array}{l}0,29 \\
0,43 \\
0,61\end{array}$ \\
\hline
\end{tabular}

Fonte: [4].

Foi necessário a realização do levantamento na NBR 15220/2005 das propriedades térmicas de cada material, que compõe as vedações verticais externas da edificação em estudo, tabela 6, para se calcular a Transmitância Térmica (U) e Capacidade térmica $\left(\mathrm{C}_{\mathrm{t}}\right)$.

Tabela 6 - Propriedades dos Materiais das paredes.

\begin{tabular}{c|c|c|c|c}
\hline Material & $\begin{array}{c}\text { Espessura } \\
\mathbf{e}(\mathbf{m})\end{array}$ & $\begin{array}{c}\text { Massa } \\
\text { específica } \\
\mathbf{\rho}\left(\mathbf{k g} / \mathbf{m}^{3}\right)\end{array}$ & $\begin{array}{c}\text { Condutividade } \\
\text { térmica } \lambda \\
{[\mathbf{W} /(\mathbf{m} . \mathbf{K})]}\end{array}$ & $\begin{array}{c}\text { Calor } \\
\text { Específico } \\
\mathbf{c} \\
{[\mathbf{k J} /(\mathbf{k g . K})]}\end{array}$ \\
\hline \\
\hline
\end{tabular}
ambiente, são somadas as resistências superfície a superfície de cada componente da parede, juntamente com a câmara de ar não ventilada, e as resistência superficiais internas e externas, para de obter o valor da propriedade, e em seguida calcula-se a Transmitância térmica (U) com a equação 1 .

A Capacidade térmica do fechamento externo é obtida a partir da soma de valores da capacidade térmica de cada elemento que são calculados pela equação 5 abaixo. Por se tratar do ar com densidade de massa aparente muito baixa $(r=1,2 \mathrm{~kg} / \mathrm{m} 3)$, em componentes que possuem câmaras de ar, despreza-se a sua capacidade térmica [4].

$$
\mathrm{C}_{\mathrm{Ti}}=\mathrm{e}_{\mathrm{i}} \mathrm{c}_{\mathrm{i}} \rho_{\mathrm{i}}
$$

Onde:

$\mathrm{C}_{\mathrm{Ti}}=$ capacidade térmica do material i do fechamento $\mathrm{kJ} /\left(\mathrm{m}^{2} . \mathrm{K}\right)$;

$\mathrm{e}_{\mathrm{i}}=$ espessura da camada $\mathrm{i}(\mathrm{m})$;

$\mathrm{c}_{\mathrm{i}}=$ calor especifico do material $\mathrm{i}(\mathrm{kJ} / \mathrm{kg} . \mathrm{K})$;

$\rho_{\mathrm{i}}=$ massa especifica do material $\mathrm{i}\left(\mathrm{kg} / \mathrm{m}^{3}\right)$. 


\section{III.2.1 COBERTURA}

A cobertura do sistema em LSF assemelha-se a de um telhado convencional, as telhas são de alumínio, de baixa emissividade e absorbância, trapezoidal, inclinada com ângulo de $20^{\circ}$ e beirais de sombreamento de $50 \mathrm{~cm}$ inclinados em todos os lados da edificação, e forro de gesso de $3 \mathrm{~cm}$, detalhes na figura 6 . A estrutura em LSF é alinhada, as almas dos perfis que compõem tesouras ou caibros são alinhada com a alma dos montantes dos painéis de apoio [16].

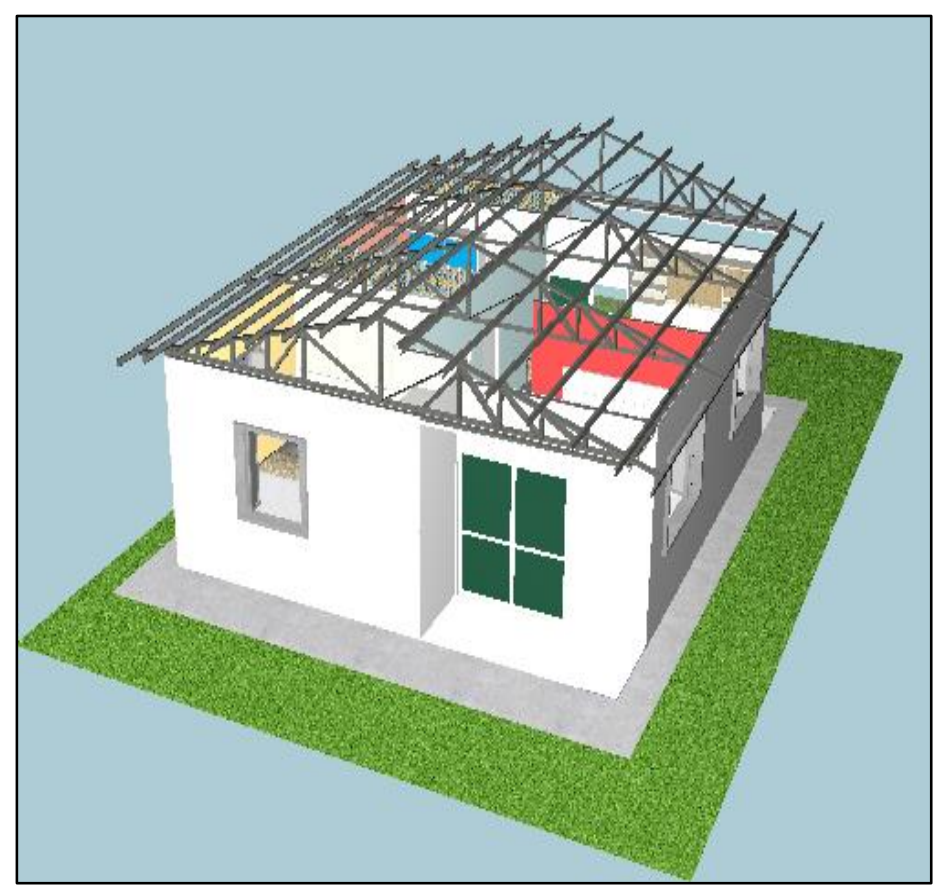

Figura 6: Detalhe de cobertura da edificação.

Os requisitos e critérios de avaliação, abordam que a Isolação térmica da cobertura deve apresentar transmitância térmica e absorbância à radiação solar que proporcionem um desempenho térmico apropriado de acordo com a zona bioclimática.

São considerados aceitáveis, os valores indicados na tabela 7, considerando o fluxo térmico descendente, o nível mínimo é de atendimento obrigatório, mas para coberturas, também são considerados outros níveis de desempenho térmico, os níveis intermediário (I) e superior (S).

Tabela 7: Níveis de desempenho e Critério - Transmitância térmica das Cobertura.

\begin{tabular}{|c|c|c|c|}
\hline 窇 & $\begin{array}{c}\text { Nível de } \\
\text { Desempenh } \\
0\end{array}$ & $\begin{array}{c}\text { Absortância a } \\
\text { radiação solar da } \\
\text { superfície externa da } \\
\text { parede }\end{array}$ & $\begin{array}{l}\text { Transmitância } \\
\text { Térmica } W / \mathbf{m}^{2} \mathbf{k}\end{array}$ \\
\hline \multirow{6}{*}{ 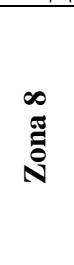 } & \multirow{2}{*}{ M } & $\alpha \leq 0,4$ & $\mathrm{U} \leq 2,3 \mathrm{FV}$ \\
\hline & & $\alpha>0,4$ & $\mathrm{U} \leq 1,5 \mathrm{FV}$ \\
\hline & \multirow{2}{*}{ I } & $\alpha \leq 0,4$ & $\mathrm{U} \leq 1,5 \mathrm{FV}$ \\
\hline & & $\alpha>0,4$ & $\mathrm{U} \leq 1,0 \mathrm{FV}$ \\
\hline & \multirow{2}{*}{$\mathrm{S}$} & $\alpha \leq 0,4$ & $\mathrm{U} \leq 1,0 \mathrm{FV}$ \\
\hline & & $\alpha>0,4$ & $\mathrm{U} \leq 0,5 \mathrm{FV}$ \\
\hline
\end{tabular}

$\mathrm{FV}=$ Fator de Ventilação estabelecido no item 2.3.3.1.

Fonte: Adaptada de [21].
Para poder verificar se a transmitância térmica da cobertura atende ao requisito da tabela 7 , deve-se calcular o FV, fator de ventilação, dado na figura 7 .

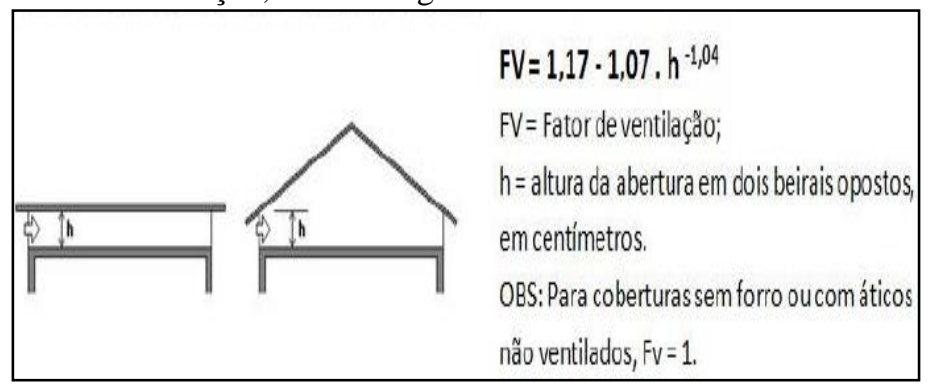

Figura 7: Abertura dos beirais e Fator de ventilação da cobertura. Fonte: [4].

\section{III.2.2.1 METODOLOGIA DE CÁLCULO DA TRANSMITÂNCIA TÉRMICA DA COBERTURA}

Para se calcular a transmitância térmica da cobertura, primeiro deve-se calcular as respectivas resistências térmicas, seguindo a metodologia acima, contudo deve-se dividir em fazes os cálculos, pois a cobertura é composta na parte exterior, em telhas de alumino, com câmara de ar ventilada e uma viga de piso como pôde-se observa na figura 8 . Em componentes com câmara de ar ventilada, faz-se uma verificação das condições de ventilação, considerando dois tipos, pouco ou muito ventiladas, segundo a sua composição. Condições são dadas na figura 8.

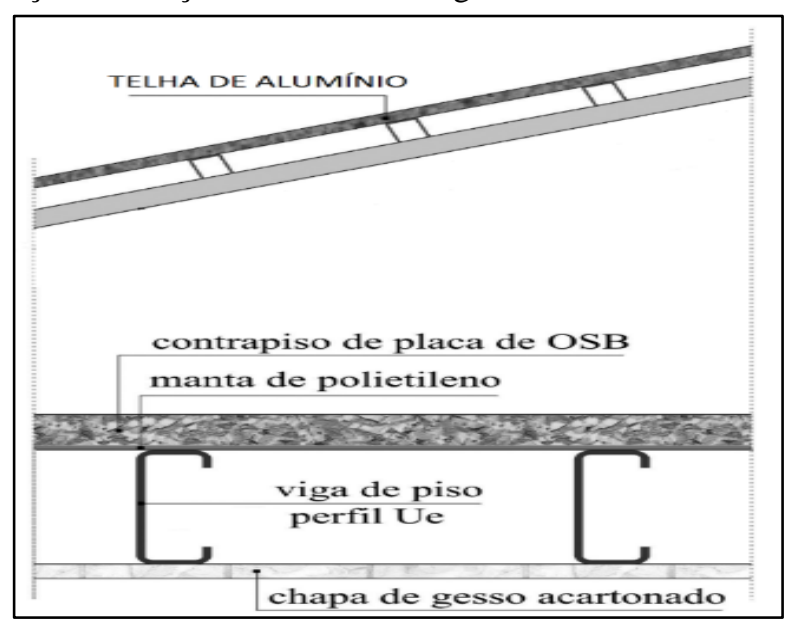

Figura 8 - Detalhe da cobertura. Fonte: [16].

Tabela 8: Condições de ventilação para câmaras de ar.

\begin{tabular}{|c|c|c|}
\hline \multirow{2}{*}{$\begin{array}{l}\text { Posição da } \\
\text { Câmara de ar }\end{array}$} & \multicolumn{2}{|c|}{ Câmara de ar } \\
\hline & Pouco ventilada & Muito ventilada \\
\hline 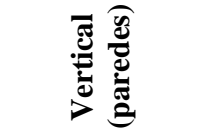 & $\mathrm{S} / \mathrm{L}<500$ & $\mathrm{~S} / \mathrm{L} \geq 500$ \\
\hline 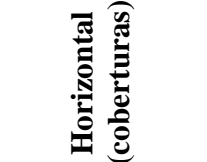 & $\mathrm{S} / \mathrm{A}<30$ & $\mathrm{~S} / \mathrm{A} \geq 30$ \\
\hline
\end{tabular}

Fonte: Adaptada de [21]. 
Em condições de verão, ou seja, ganho de calor, a resistência térmica da câmara de ar ventilada deve ser igual à da câmara de ar não ventilada e obtida na tabela 5. Atentando a emissividade, espessura e fluxo de calor.

O cálculo da resistência térmica total ambiente a ambiente do conjunto cobertura, utiliza-se a equação 2 , modificando os componentes, para os utilizados na cobertura, assim como na equação 6 , mas primeiramente calcula-se a resistência superfície a superfície da cobertura, que por sua vez compõe a resistência total de ambiente a ambiente da viga de piso, equação 7 .

Logo para determinar a resistência de ambiente a ambiente da viga de piso, são necessários calcular as resistências superfície a superfície da viga de piso, constituído da resistência externa e interna, como na equação 3 , modificada para equação 8 .

A Resistencia térmica da viga de piso é determinada pelo cálculo das resistências de cada componente da viga junto com a câmara de ar, equação 9. Todas as equações citadas acima, são dispostas na tabela 9, abaixo.

Tabela 9: Equações para obtenção da Transmitância térmica da cobertura.

\begin{tabular}{|c|c|c|c|}
\hline Equação 6 & Equação 7 & Equação 8 & Equação 9 \\
\hline $\mathrm{R}_{\mathrm{t}}=\mathrm{R}_{\mathrm{SE}}+\mathrm{R}_{\mathrm{t}}$ & $\mathrm{R}_{\mathrm{t} \text { corbertura }}=\mathrm{R}_{\mathrm{t}}$ & $\mathrm{R}_{\mathrm{T} \text { viga de piso }}$ & $\mathrm{R}_{\mathrm{t} \text { viga de piso }}=\mathrm{R}_{\mathrm{t}}$ \\
cobertura $+\mathrm{R}_{\mathrm{SI}}$ & telha de alumínio + & $=\mathrm{R}_{\mathrm{SE}}+\mathrm{R}_{\mathrm{t}}$ & gesso acartonado $+\mathrm{R}_{\mathrm{t}}$ \\
$\left(\mathrm{m}^{2} . \mathrm{K} / \mathrm{W}\right)$ & $\mathrm{R}_{\mathrm{ar}}+\mathrm{R}_{\mathrm{T} \text { viga de }}$ & viga de piso & OSB $+\mathrm{Rar}+\mathrm{R}_{\mathrm{t}}$ \\
& piso $\left(\mathrm{m}^{2} . \mathrm{K} / \mathrm{W}\right)$ & $\mathrm{R}_{\mathrm{SI}}$ & manta de polietileno \\
& & $\left(\mathrm{m}^{2} . \mathrm{K} / \mathrm{W}\right)$ & $\left(\mathrm{m}^{2} . \mathrm{K} / \mathrm{W}\right)$ \\
& & & \\
& &
\end{tabular}

Fonte: Adaptada da [4].

Assim, calcula-se as resistências de cada elemento que compõe a viga de piso equação 4 , para chegar a resistência térmica superfície a superfície da viga de piso, como também a resistência térmica da telha de alumínio, e as propriedades de cada material foram especificadas na [4] como também pelo fabricante do produto, tabela 10, dado necessários para calcular a Transmitância Térmica (U) e Capacidade térmica $\left(C_{T}\right)$, da cobertura.

Tabela 10 - Propriedades dos materiais da cobertura.

\begin{tabular}{|c|c|c|c|c|}
\hline \multicolumn{5}{|c|}{ Material } \\
\hline & $\begin{array}{l}\text { Telha de } \\
\text { Alumínio }\end{array}$ & $\begin{array}{c}\text { Gesso } \\
\text { acartonado }\end{array}$ & $\begin{array}{c}\text { Manta de } \\
\text { Polietileno }\end{array}$ & $\begin{array}{l}\text { Placa } \\
\text { OSB }\end{array}$ \\
\hline 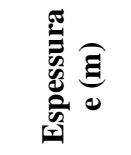 & 0,038 & 0,0125 & 0,002 & 0,0111 \\
\hline 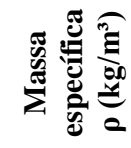 & 2700 & 750 & 33 & 450 \\
\hline 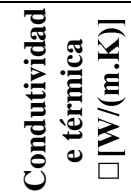 & 230 & 0,35 & 0,035 & 0,12 \\
\hline 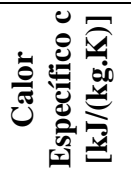 & 0,88 & 0,84 & 0,60 & 2,30 \\
\hline
\end{tabular}

Fonte: [4][22][23].

\section{RESULTADOS E DISCUSSÕES}

Este estudo teve como propósito compreender o desempenho térmico de uma edificação em Light Steel Framing na cidade de Manaus-AM, bem como identificar a zona bioclimática da cidade, e caracterizar a geometria da edificação em fase de projeto adaptando-a ao clima local, junto com a identificação dos requisitos e critérios de avaliação de desempenho térmico, da parede externa e cobertura, para então poder discutir como a edificação se comporta em relação ao desempenho térmico em regiões de clima quente e úmido. A finalidade do estudo foi que com a avaliação do desempenho térmico de uma edificação em LSF poderia verificar se a edificação atende aos níveis mínimos de desempenho exigidos pela [1], e assim poder ajudar na escolha do sistema construtivo, no uso dessa nova tecnologia construtiva na cidade, que promete um desempenho térmico superior aos sistemas construtivos convencionas, isso porque conforme a norma de desempenho, [1] "a avaliação de desempenho busca analisar a adequação ao uso de um sistema ou de um processo construtivo destinado a cumprir uma função, onde é realizada uma investigação baseada em métodos consistentes, capazes de produzir uma interpretação objetiva sobre o comportamento esperado do sistema nas condições de uso definidas". Seguindo essa premissa, vê-se que é possível essa avaliação mostrar se a edificação em LSF possui um desempenho térmico adequado.

As condições climáticas, quanto, a adequação da edificação os critérios das normas tomada por base, e plano diretor, as aberturas dos ambientes de longa permanência foram atendidas, pois a área de ventilação mostrou-se superior a 20\%, (Tabela 1) o que se trata de otimizar a troca de temperatura dos ambientes, com o aumento da entrada da ventilação natural, indispensável nas recomendações e diretrizes construtivas conectada ao conforto térmico. Em relação as paredes e cobertura, e os critérios da norma, a tabela 11 abaixo destaca-se os resultados dos cálculos das propriedades térmicas, vale destacar que a absorbância à radiação solar da superfície $(\alpha)$ é de 0,4 para ambas.

Tabela 11: Resultado - Paredes externas e Cobertura.

\begin{tabular}{|c|c|c|c|c|c|}
\hline \multirow{2}{*}{ تֶֶ } & \multicolumn{2}{|c|}{ Critérios - Zona 8} & \multicolumn{2}{|c|}{ Resultado } & \multirow{2}{*}{ Nível } \\
\hline & Transn & ância térmica (U) & $\mathrm{U}$ & $\mathrm{Ct}$ & \\
\hline \multirow{2}{*}{ 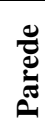 } & & $\alpha \leq 0,6$ & \multirow{2}{*}{$\begin{array}{l}0,5399 \\
W / \mathrm{m}^{2} \cdot \mathrm{k}\end{array}$} & \multirow{2}{*}{$\begin{array}{c}7,8855 \\
\mathrm{~kJ} / \mathrm{m}^{2} . \\
\mathrm{K}\end{array}$} & \multirow{2}{*}{$\begin{array}{l}\text { Nível } \\
\text { Mínim } \\
\text { o }\end{array}$} \\
\hline & & $\mathrm{U} \leq 3,7$ & & & \\
\hline \multirow{4}{*}{ ن⿺辶ّ } & & $\alpha \leq 0,4$ & \multirow{4}{*}{$\begin{array}{c}0,6824 \\
\mathrm{~W} /\left(\mathrm{m}^{2} .\right. \\
\mathrm{k})\end{array}$} & \multirow{4}{*}{ - } & \multirow{4}{*}{$\begin{array}{l}\text { Nível } \\
\text { Superi } \\
\text { or }\end{array}$} \\
\hline & $\begin{array}{c}U \leq \\
2,2293\end{array}$ & Nível Mínimo & & & \\
\hline & $\begin{array}{c}U \leq \\
1,4539\end{array}$ & $\begin{array}{c}\text { Nível } \\
\text { Intermediário }\end{array}$ & & & \\
\hline & $\begin{array}{c}U \leq \\
0,9693\end{array}$ & Nível Superior & & & \\
\hline
\end{tabular}

A Transmitância térmica e a capacidade térmica mostramse dentro dos critérios estabelecidos na [20] e nível de desempenho térmico da parede atende as premissas técnicas do nível mínimo de desempenho térmico.

Como na análise de desempenho térmico pelo procedimento simplificado os níveis aceitáveis de transmitância térmica são de até $3,7 \mathrm{~W} /\left(\mathrm{m}^{2} . \mathrm{k}\right)$, percebe-se que a transmissão de 
calor das paredes em LSF é muito inferior. Também pode ser observado, que a cobertura está perfeitamente dentro desses limites aceitáveis para se obter um nível de desempenho superior.

A importância da identificação da zona bioclimática foi destacar as diretrizes construtivas e as estratégias de condicionamento térmico adequado ao clima da região a ser estudada, bem como conforme a parte três da [4] "o conjunto de recomendações técnico-construtivas otimizam o desempenho térmico da edificação, através de sua melhor adequação climática". Vê-se que adequando a edificação ao clima local, pode-se otimizar o desempenho térmico da mesma. As estratégias das diretrizes construtivas com relação a essa zona bioclimática, das vedações externas e cobertura, visa o desempenho térmico da edificação, adaptada ao clima local, determinado no zoneamento Bioclimático brasileiro, tabela 12 .

Tabela 12: Diretrizes construtivas para adequação da edificação ao clima local.

\begin{tabular}{|c|c|c|c|c|}
\hline \multicolumn{2}{|c|}{$\begin{array}{l}\text { Vedações } \\
\text { externas }\end{array}$} & $\begin{array}{c}\text { Transmitância } \\
\text { térmica }\end{array}$ & $\begin{array}{c}\text { Atraso } \\
\text { Térmico }\end{array}$ & $\begin{array}{l}\text { Fator } \\
\text { solar }\end{array}$ \\
\hline \multirow{2}{*}{ 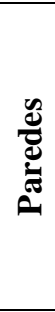 } & 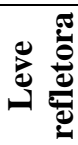 & $\mathrm{U} \leq 3,60$ & $\varphi \leq 4,3$ & $\mathrm{FS}_{\mathrm{o}} \leq 4,0$ \\
\hline & 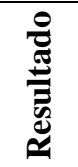 & 0,5399 & $\varphi=2,1 \mathrm{~h}$ & $4,3 \%$ \\
\hline \multirow{2}{*}{ نِّ } & لِّ & $\mathrm{U} \leq 2,30$ & $\varphi \leq 3,3$ & $\mathrm{FS}_{\mathrm{o}} \leq 6,5$ \\
\hline & 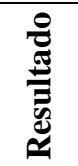 & 0,6824 & $\varphi=3,2 \mathrm{~h}$ & $1,4 \%$ \\
\hline
\end{tabular}

As paredes e coberturas, se tratando de "leve refletora", pode-se dizer a características térmica do elemento, com relação à transmissão, retenção e fator solar, atende parcialmente aos limites de cada característica. Como pode-se observar na tabela 12, a edificação está quase que totalmente adequada a esses fatores, porem o fator solar da parede verificada está um pouco acima do limite, nada que influenciem diretamente no conforto térmico da edificação, por esse motivo a parte três da [4], mostra que "a zona bioclimática da região aborda os elementos climáticos que interferem nas relações entre ambiente construído e conforto humano". Deste modo, obedecendo as diretrizes construtivas da zona bioclimática que a cidade em estudo pertence, e adequando a edificação ao clima local, vê-se que o desempenho térmico podese ser obtido unido com o conforto térmico do usuário.

Com a caracterização da edificação, pode-se observar que é uma residência unifamiliar térrea de $64,80 \mathrm{~m}^{2}$ e foi adequada para o sistema construtivo em LSF, os painéis de fechamento são estruturais, compostos por perfis de aço galvanizado, de montante em U enrijecido (90x40), na cobertura a estrutura alinhada as almas dos painéis de apoio, a fundação utilizada é do tipo radier e os requisitos e critérios das vedações verticais externas e cobertura é dado conforme as [20] e [1] respectivamente. Pode-se destacar que foi adicionado uma malha geométrica modular de 600 x 600 mm para adequar ao LSF, os fechamentos são compostos de placas cimentícias na camada externa e placas de gesso acartonado na camada interna, seu interior, são preenchidos com lã de vidro, uma camada de ar, a cobertura é composta na parte exterior, em telhas de alumino, com ático e uma viga de piso com forro. Assim a parte um da norma de desempenho [1] destaca que "os requisitos de desempenho expressam qualitativamente os atributos que a edificação habitacional e seus sistemas devem possuir, a fim de que possam satisfazer as exigências do usuário". Significando que quando atendido todos os requisitos e critérios, o nível de desempenho estabelecido é o nível mínimo.

Obedecendo a metodologia de cálculo da [4] e do mesmo procedimento simplificado de análise, nos estudos de [18], as propriedades térmicas da edificação em LSF não atendeu aos requisitos normativos quanto a capacidade térmica, mas com relação a transmitância térmica, o requisito foi atendido com facilidade. Vale destacar que o fechamento em LSF abordado estudo, são compostos pelo sistema de isolamento EIFS, com composição diferente do utilizando neste estudo, e ainda a zona bioclimática referida por [18] é a zona 3. Portanto os resultados se difere, diante da mudança da zona bioclimática e da composição do fechamento em LSF.

Nos estudos de [19], os resultados foram obtidos pela mesma metodologia aqui abordada, assim a transmitância térmica encontrada foi satisfatória para os critérios de desempenho da zona bioclimática oito, e a cobertura satisfaz o nível intermediário de desempenho térmico, entretanto a análise foi feita em um edifício, na unidade do último andar, com cobertura exposta, e o sistema construtivo utilizado é convencional com alvenaria modular. Desta forma, pode-se observar que mesmo com sistemas construtivos diferentes, pode-se obter o nível mínimo de desempenho térmico, se tratando da mesma zona bioclimática.

Os resultados dos cálculos das propriedades térmicas das paredes externas e cobertura, focados em obter dados sobre o desempenho térmico da edificação em LSF, mostram que na parede externa a transmissão de calor foi de $0,5399 \mathrm{~W} /\left(\mathrm{m}^{2} . \mathrm{k}\right)$, facilmente de acordo com os requisitos e critérios da avaliação de desempenho térmico do procedimento simplificado, logo a capacidade térmica de $7,8855 \mathrm{~kJ} /\left(\mathrm{m}^{2} . \mathrm{K}\right)$, não tem exigências de critério, já na cobertura o nível de desempenho térmico satisfaz o nível superior, pois a Transmissão de calor de $0,6824 \mathrm{~W} /\left(\mathrm{m}^{2} . \mathrm{k}\right)$ mostra-se muito abaixo do nível mínimo, assim entende-se que os resultados do desempenho térmico foram otimizados pois a edificação foi adequada ao clima local, com a estratégia de ventilação cruzada e aberturas de ventilação grandes, permitindo a circulação do ar.

Diante disso, realizado os procedimentos de avaliação do desempenho térmico de sistemas construtivos, é possível afirmar que o desempenho térmico da edificação analisada, possui o nível mínimo de desempenho, ou seja o comportamento térmico em uso da edificação e de seus sistemas são adequados para o usuário.

\section{CONCLUSÃO}

O desenvolvimento do presente estudo possibilitou analisar o comportamento do sistema construtivo LSF de uma edificação, quanto ao seu desempenho térmico, conforme procedimentos 1 da norma de desempenho [1], como também poder contribuir com o uso dessa nova tecnologia construtiva na cidade de Manaus [24].

De um modo geral, o desempenho térmico da edificação aliado a adequação da edificação ao clima local na fase de projeto, apresenta desempenho térmico satisfatório, em que as paredes externas obedecem aos requisitos normativos, com o 
desempenho mínimo e a cobertura por sua vez atende ao nível superior de desempenho térmico, que são capazes de proporcionar conforto térmico aos usuários. A adequação as diretrizes construtivas da zona bioclimática 8 possibilitou um maior aproveitamento da ventilação dos ambientes de longa permanência, com a ventilação cruzada uma estratégia de condicionamento térmico passivo. Percebeu-se que todos os requisitos propostos pela norma de desempenho foram atendidos pela edificação analisada.

$\mathrm{O}$ procedimento simplificado de avaliação do desempenho térmico de sistemas construtivos da [1], possibilitou obter um resultado satisfatório da edificação. A metodologia de cálculo das propriedades térmicas dos materiais, Transmitância Térmica (U) e Capacidade Térmica (Ct), mostrou importância de seguir o procedimento de cálculo da [4] para se chegar aos resultados das propriedades térmicas. Dada a importância do tema, torna-se necessário o desenvolvimento de estudos que abordam mais profundamente o desempenho térmico das edificações, tendo por principal função despertar no setor da construção civil o hábito da adequação das edificações ao clima local e na obtenção do seu desempenho térmico. Nesse sentido, com a avaliação do desempenho térmico da edificação em LSF, pode-se verificar o desempenho térmico obtido, de tal modo que todos os requisitos e critérios propostos pela norma de desempenho de edificações foram atendidos, podendo assim dizer que a edificação construída com o sistema construtivo Light Steel Framing na cidade de Manaus-AM possui o desempenho térmico de nível mínimo, possibilitando ao menos um conforto térmico mínimo para o usuário.

\section{AGRADECIMENTOS}

Ao Instituto de Tecnologia e Educação Galileo da Amazônia (ITEGAM) e ao Laureate Universities International (UNINORTE) pelo apoio à pesquisa.

\section{REFERÊNCIAS}

[1] ASSOCIAÇÃO BRASILEIRA DE NORMAS TÉCNICAS ABNT. NBR 15575: Edificações habitacionais - Desempenho Parte 1: Requisitos Gerais, Rio de Janeiro, 2013.

[2] HEYER, L. F., Manaus - Um exemplo de clima urbano em região subequatorial. 1997. 198 f. Tese (Doutorado Em Geografia). Universidade de São Paulo - USP, São Paulo, 1997.

[3] Nascimento, B. A. R.; Araújo, V. S.; Análise Do Desempenho Térmico De Edificações De Steel Frame E Alvenaria Estrutural Em Manaus-Am. CONTECC. Fortaleza-CE, 2015.

[4] ASSOCIAÇÃO BRASILEIRA DE NORMAS TÉCNICAS ABNT. NBR 15575: Edificações habitacionais - Desempenho Parte 3: Requisitos Gerais, Rio de Janeiro, 2013.

[5] ASSOCIAÇÃO BRASILEIRA DE NORMAS TÉCNICAS ABNT. NBR 15220: Desempenho térmico de edificações - Parte 3: Zoneamento Bioclimático brasileiro e diretrizes construtivas para habitações unifamiliares de interesse social. Rio de Janeiro, 2005.
[6] SANTIAGO, A. K.; FREITAS, A. M. S.; CASTRO, R. C. M. de; Steel Framing: Arquitetura. 2. ed. Rio de Janeiro: IBS/CBCA, Série Manual da Construção em Aço, 2012.

[7] SZOKOLAY, S.V., Environmental Science Handbook. Lancaster, England: The Construction Press Ltd., 1980. 531 p.

[8] GOMES, A. P. Método de Avaliação do desempenho térmico de edifícios comerciais e residenciais em light steel framing. 2012. 147 f. Tese (Doutorado em Engenharia Civil) DECIV/UFOP, Ouro Preto, 2012.

[9] www.reformolar.com.br. 2016. Acesso em 17.10.2016.

[10] IBGE. Instituto Brasileiro de Geografia e Estatística. 2010. Disponível

<http://cidades.ibge.gov.br/xtras/perfil.php?codmun=130260>

Acesso em: 20 de abril de 2016.

[11] SUFRAMA. Superintendência da Zona Franca de Manaus. 2000. Disponível em: <http://www.suframa.gov.br/zfm_turismo_manaus.cfm> Acesso em: 20 de abril de 2016.

[12] SCHIFFER, S. R.; FROTA, A. B., Manual de Conforto Térmico, 7.ed. São Paulo: Studio Nobel, 2003.

[13] LOUREIRO, K. C. G.; Análise de desempenho térmico e consumo de energia de Residências na cidade de Manaus. 2003. 139p. Dissertação (Mestrado em Engenharia Civil) - Curso de PósGraduação em Engenharia Civil, UFSC, Florianópolis, 2003.

[14] Lima, Tomás Bastos. Análise de desempenho térmico de edificações habitacionais: desenvolvimento de interface BIM para avaliações automatizadas segundo as normas ABNT NBR 15575 e ABNT NBR 15220. TCC do Curso de Engenharia Civil da Universidade Federal do Paraná (UFPR). 2013.

[15] Propriedades de Materiais - Alguns Plásticos. Disponível em: <http://www.mspc-eng.br/cmat310.shtl> Acesso em 10 de setembro de 2016 .

[16] GOMES, A. P. Avaliação do desempenho térmico de edificações unifamiliares em Light steel framing. 2007. 172 f. Dissertação (Mestrado em Engenharia Civil) - DECIV/UFOP, Ouro Preto, 2007.

[17] Muzzi, T. A. Métodos de avaliação da resistência e transmitância térmicas do sistema de fechamento em Light Steel Framing. 2014. 110 f. Dissertação (Mestrado em Engenharia Civil) - Escola de Minas, Universidade Federal de Ouro Preto, Ouro Preto, 2014.

[18] MAGALHÃES, R. F.; Edificações em Light Steel Frame isoladas externamente com Eifs: Avaliação de Desempenho Térmico pela NBR 15.575/2013. 2013. 92 f. Monografia (Graduação em Engenharia Civil) - UFRS, Porto Alegre, 2013.

[19] Calazans, Camila Julia. Análise da ABNT NBR 15575:2013 com ênfase em desempenho térmico. TCC apresentado ao Curso de Especialização: Produção e Gestão do Ambiente Construído do Departamento de Engenharia de Materiais e Construção, da Escola de Engenharia da Universidade Federal de Minas Gerais (EE-UFMG). 2016. 
[20] ASSOCIAÇÃO BRASILEIRA DE NORMAS TÉCNICAS ABNT. NBR 15575: Edificações habitacionais - Desempenho Parte 4: Requisitos Gerais, Rio de Janeiro, 2013.

[21] ASSOCIAÇÃO BRASILEIRA DE NORMAS TÉCNICAS ABNT. NBR 15575: Edificações habitacionais - Desempenho Parte 5: Requisitos Gerais, Rio de Janeiro, 2013.

[23] Jamantha - Manta térmica. Disponível em: <http://www.jamantha.com.br> Acesso em 12 de setembro de 2016.

[24] MANAUS, 2014. Projeto de Lei do Plano Diretor Urbano e Ambiental do Município de Manaus. Lei complementar ${ }^{\circ}$ 002, de 16 de janeiro de 2014 .

[25] www.mspc-eng.br (2016). Acesso em 10.09.2016. 